\title{
Augmented Adsorptive Blood Purification during Continuous Veno-Venous Haemodiafiltration in a Severe Septic, Acute Kidney Injury Patient: Use of oXiris ${ }^{\circledR}$ : A Single Centre Case Report
}

\author{
Han Khim Tan ${ }^{a}$ Manish Kaushik ${ }^{a}$ Chee Wooi Tan ${ }^{a}$ Zhong Hong Liew ${ }^{\mathrm{a}}$ \\ Su Hooi Teo ${ }^{a}$ Chian Min Loo ${ }^{b} \quad$ Li Choo Ng $^{\text {a }}$ Lina Hui Lin Choong ${ }^{a}$ \\ Marjorie Wai Yin Foo ${ }^{a}$ \\ a Department of Renal Medicine, Singapore General Hospital, Singhealth-Duke Academic Medical Centre, Singapore, \\ Singapore; ${ }^{b}$ Department of Respiratory and Critical Care Medicine, Singapore General Hospital, Singhealth-Duke \\ Academic Medical Centre, Singapore, Singapore
}

\section{Keywords}

Adsorption · Severe sepsis · Acute kidney injury

\begin{abstract}
The use of the oXiris ${ }^{\circledR}$ haemofilter during continuous venovenous haemodiafiltration (CVVHDF) for acute kidney injury (AKI) and severe sepsis is not completely understood. Although this filter has in vitro adsorptive properties for bloodborne cytokines and other humoural mediators of sepsis, its clinical usefulness is uncertain. Given its inherent adsorptive limitation for septic mediators, we developed a CVVHDF protocol in which the oXiris haemofilter was electively changed every $12 \mathrm{~h}$ even though there was no clotting or adverse circuit pressures. Augmented filter membrane adsorption was conducted for 3 consecutive days. We treated a critically ill patient with severe sepsis secondary to a gram-negative bacterial infection and sepsis-associated acute kidney injury (SA- AKI) in this way. The patient required high-dose vasopressor support, required mechanical ventilation, had received $12 \mathrm{~h}$ of CVVHDF with conventional M100 haemofilter,
\end{abstract}

was on broad spectrum antibiotics and other conventional intensive care unit (ICU) care, prior to institution of the frequent oXiris haemofilter change protocol. Following the start of elective 12 hourly oXiris filter change, the patient showed reduction in the need for vasopressor and by Day 4 of this SA- AKI frequent filter change protocol, vasopressor requirement ceased, he was extubated. He survived ICU and but not hospital stay. To this end, more clinical studies are needed.

\footnotetext{
(C) 2019 The Author(s)

Published by S. Karger AG, Base
}

\section{Introduction}

The use of continuous renal replacement therapy (CRRT) was shown to ameliorate severe human sepsis. Septic mediators could be eliminated and norepinephrine dose reduced when such patients were treated with intermittent $8 \mathrm{~h}$ high volume haemofiltration of $6 \mathrm{~L} / \mathrm{h}$ compared to $1 \mathrm{~L} / \mathrm{h}$ for similar duration [1]. Apart from ultrafiltration, adsorption with a device for gram-negative sepsis

\begin{tabular}{|c|c|}
\hline KARGER & $\begin{array}{l}\text { (C) } 2019 \text { The Author(s) } \\
\text { Published by S. Karger AG, Basel }\end{array}$ \\
\hline $\begin{array}{l}\text { E-Mail karger@karger.com } \\
\text { www.karger.com/bpu }\end{array}$ & $\begin{array}{l}\text { This article is licensed under the Creative Commons Attribution- } \\
\text { NonCommercial-NoDerivatives } 4.0 \text { International License (CC BY- } \\
\text { NC-ND) (http://www.karger.com/Services/OpenAccessLicense). } \\
\text { Usage and distribution for commercial purposes as well as any dis- } \\
\text { tribution of modified material requires written permission. }\end{array}$ \\
\hline
\end{tabular}

Prof. Han Khim Tan

Department of Renal Medicine

Singhealth-Duke Academic Medical Centre

The Academia, Level 3 Singapore 169608 (Singapore)

E-Mail tan.han.khim@singhealth.com.sg 
also showed no survival advantage in a Phase II study [2]. Adsorption devices can either be powdered sorbent columns or membranes. The latter include AN69 Surface Treated (AN69ST), polymethylmetacrylate and oXiris membranes [3]. oXiris ${ }^{\circledR}$ is a modified AN69ST membrane and has affinity for both endotoxins and cytokines. It consists of a proprietary 3 layer membrane structure. The base membrane is AN69, which is surface treated with polyethyleneimine and heparin is grafted to reduce membrane thrombogenicity [4]. When used clinically, oXiris-continuous veno-venous haemofiltration $(\mathrm{CVVH})$ was shown to reduce SOFA score after $48 \mathrm{~h}$ compared to historical controls treated with polysulfone CVVH. No in-hospital mortality or intensive care unit (ICU) mortality differences were observed between both groups. Mean oXiris circuit life was $61 \mathrm{~h}$. No elective circuit change was performed [5]. A recent in vitro haemoperfusion study compared oXiris with other adsorption devices. oXiris showed similar adsorption for endotoxin compared to immobilized Polymyxin-B column (Toraymycin) at $2 \mathrm{~h}$, and it also had similar adsorptive profile as Cytosorb for cytokines and other inflammatory mediators. However, endotoxin removal by Cytosorb was minimal. Thus, oXiris seemed to be the most "broad-spectrum" device with adsorptive affinity for both endotoxins and cytokines [6]. Given that there is no clinical data on the use of frequent filter change in augmenting the adsorptive elimination of endotoxins and cytokines, we developed a blood purification protocol to achieve this using the oXiris membrane during continuous veno-venous haemodiafiltration (CV VHDF) for severe sepsis-associated acute kidney injury (SA-AKI) to determine if clinical response was favourable or not. We hereby report our proposed protocol and our experience in a single case.

\section{Proposed Protocol for Augmented Adsorptive Blood Purification using Modified, Heparin-Grafted AN69ST Membrane (oXiris)}

Patients with acute kidney injury (AKI) and haemodynamic instability are treated in our institution with CRRT in CVVHDF with post-filter replacement mode, using the Prismaflex CRRT platform (Baxter Corporation, Deerfield, IL, USA). PrismasolB0 solution is used as both dialysate and haemofiltration replacement fluid, with additives potassium chloride and potassium dihydrogen phosphate added to PrismasolB0 bags, in accordance with serum electrolyte levels, which are checked at $4-8$ hourly intervals as clinically indicated. The oXiris haemofilter was used in our internally developed blood purification protocol instead of the standard M100 CRRT haemofilter. However, instead of using the oXiris filter until spontaneous clotting and circuit loss occurs, the oXiris filter was changed electively after every $12 \mathrm{~h}$ for first $72 \mathrm{~h}$. This ensured that a fresh membrane was made available for adsorption of cytokines and endotoxins, and thereby modulates the course and severity of severe sepsis and septic shock.

\section{Case Presentation}

The patient was a 59-year-old male with Child's B alcoholic liver cirrhosis complicated by multifocal hepatocellular carcinoma, ascites and esophageal varices (Table 1). He was admitted with shock secondary to klebsiella pneumoniae bacteremia, blood pressure was 76/45 mm Hg and serum lactate $8.4 \mathrm{mmol} / \mathrm{L}$ (normal: $0.5-2.2 \mathrm{mmol} / \mathrm{L}$ ). Noradrenaline and mechanical ventilation in the ICU were instituted. Antimicrobial therapy with intravenous meropenem and amikacin was also administered. He did not have suppurative disease of his hepatobiloary system but had developed oliguric AKI. CVVHDF, via a right central venous femoral dialysis catheter, at $35 \mathrm{~mL} / \mathrm{kg} / \mathrm{h}$ with post-filter replacement fluid was commenced approximately $20 \mathrm{~h}$ after admission for worsening SA-AKI, high anion gap metabolic acidosis and oliguria despite medical management. CVVHDF was performed using the Prismaflex CRRT machine (Baxter, Deerfield, IL, USA) and conventional M100 haemofilter. In the first $12 \mathrm{~h}$ after CVVDF initiation, the patient's haemodynamic status, vasopressor requirement and fractional inspired oxygen remained unchanged or continued to worsen (Fig. 1). After consent from patient's family, we implemented the proposed frequent oXiris haemofilter change protocol from Day 2 of ICU admission onwards. It involved oXiris haemofilter change every $12 \mathrm{~h}$ even though the extraorporeal circuit was working well. This enhanced adsorptive blood purification protocol was continued for 3 consecutive days. The dose and number of vasopressors needed to maintain haemodynamic stability were progressively reduced over the 3-day treatment period and finally ceased by the fourth day of start of frequent oXiris haemofilter change protocol (Fig. 1). Soon after that, the patient was extubated on Day 6 of ICU admission. The patient had partial AKI recovery on Day 6 of ICU stay, evidenced by increasing urine output and decreasing serum creatinine, which resulted in the discontinuation of CVVHDF (Table 2). He was discharged from ICU to step down intermediate care area on Day 6 of admission. He received a single session of intermittent dialysis on Day 9 of hospital admission, before being transferred to the general ward. Additional complications during the hospital course included decompensation of alcoholic liver disease complicated by oesophageal variceal bleed requiring blood transfusions, sepsis, hepatic encephalopathy and second episode of AKI. Despite administration of intravenous albumin, antimicrobial treatment and other supportive measures including blood transfusion for bleeding from gastrointestinal tract, he continued to deteriorate. Given his multiple co-morbidities, he was assessed to be medically unfit for liver transplant. The patient and his family opted for conservative management of his end-stage liver disease and non-dialytic management for his AKI. He eventually succumbed 27 days after ICU discharge with a total hospitalisation duration of 32 days.
60

Blood Purif 2019;47(suppl 3):59-64 DOI: $10.1159 / 000499633$
Tan/Kaushik/Tan/Liew/Teo/Loo/Ng/ Choong/Foo 
Table 1. Demographic and clinical data of patient

\begin{tabular}{ll}
\hline Age/gender/race & $59 /$ M/Chinese \\
\hline Clinical diagnoses & $\begin{array}{l}\text { Acute Klebsiella pneumoniae bacteraemia } \\
\text { and septic shock complicated by AKI; } \\
\text { Background history: } \\
\text { Child's C alcoholic liver cirrhosis } \\
\text { Multifocal HCC }\end{array}$ \\
& $\begin{array}{l}\text { Chronic ascites } \\
\text { Oesophageal varices }\end{array}$ \\
\hline AKI on CVVHDF & Yes \\
\hline Broad-spectrum antimicrobials & Yes \\
\hline Time after ICU admission before frequent oXiris haemofilter & Meropenem, Amikacin \\
change was started, days & 2 \\
Duration in ICU before discharge, days & 6 \\
\hline $\begin{array}{l}\text { ICU/hospital survival } \\
\text { cause of death }\end{array}$ & Yes/No \\
& Hepatorenal syndrome on non-dialytic \\
& management with decompensated liver \\
\end{tabular}

AKI, acute kidney injury; HCC, hepatocellular carcinoma; ICU, intensive care unit.

\section{Discussion and Conclusion}

CRRT is the established treatment for severe AKI in critically ill patients [7]. Studies have shown that haemofiltration can remove cytokines and potentially immunomodulate the course of severe sepsis. Cole et al. [1] observed that high-volume haemofiltration at $6 \mathrm{~L} / \mathrm{h}$ for $8 \mathrm{~h}$ reduced vasopressor requirements in septic shock significantly compared to standard CVVH of $1 \mathrm{~L} / \mathrm{h}$. With a lower ultrafiltration rate of $2 \mathrm{~L} / \mathrm{h}$, cytokines were still removed from the systemic circulation in the ultrafiltrate but not enough to reduce the plasma cytokine concentrations in patients with severe sepsis but no AKI [8]. Interest in ultrafiltration as a blood purification method culminated in studies such as the IVOIRE study. This randomized controlled trial compared high-volume haemofiltration at $70 \mathrm{~mL} / \mathrm{kg} / \mathrm{h}$ versus standard-volume haemofiltration at $35 \mathrm{~mL} / \mathrm{kg} / \mathrm{h}$ for a $96-\mathrm{h}$ treatment period in AKI patients. The 28-day mortality, haemodynamic profile improvements and organ functions were not significantly different between the 2 groups. Thus, high-volume haemofiltration was not more effective than standard volume haemofiltration in the treatment of septic shock complicated by AKI [9].

Adsorption in blood purification for severe sepsis can be achieved using either membranes or sorbents. Powdered sorbent pheresis was developed in coupled plasma filtration adsorption (CPFA) for the treatment of severe sepsis. In one study, CPFA was added to standard care with those randomized to study arm receiving 5 days of $10 \mathrm{~h}$ CPFA per day. Mortality and other end points were not improved in those who received CPFA and standard care [10]. Sorbents remain potentially useful although its clinical benefit has not yet been proven to date [11]. Another development has been in the area of membranes used in CRRT. A novel asymmetric triacetate (ATA) membrane was compared with 3 other membranes in an in vitro study. ATA was shown to have relatively higher permeability to cytokines, lower thrombogenicity and fouling compared to polysulfone, polyethersulfone and AN69 ST membranes [12]. These features of the ATA membrane may translate into useful properties during CRRT. Another development has been in the modification of the AN69 ST membrane - oXiris. It has affinity for adsorptive clearance of both endotoxins and cytokines from the circulation $[3,6]$. However, little is known about the saturation limit of oXiris membr during CRRT or the optimal duration of its use. In a study by Shum et al. [5], it was used as a conventional CRRT membrane with mean circuit life of $61 \mathrm{~h}$ per oXiris circuit. Used in this way, the adsorptive capacity of this membrane could have been saturated and not fully exploited before spontaneous circuit clotting occurred. One way to do so is to elec- 

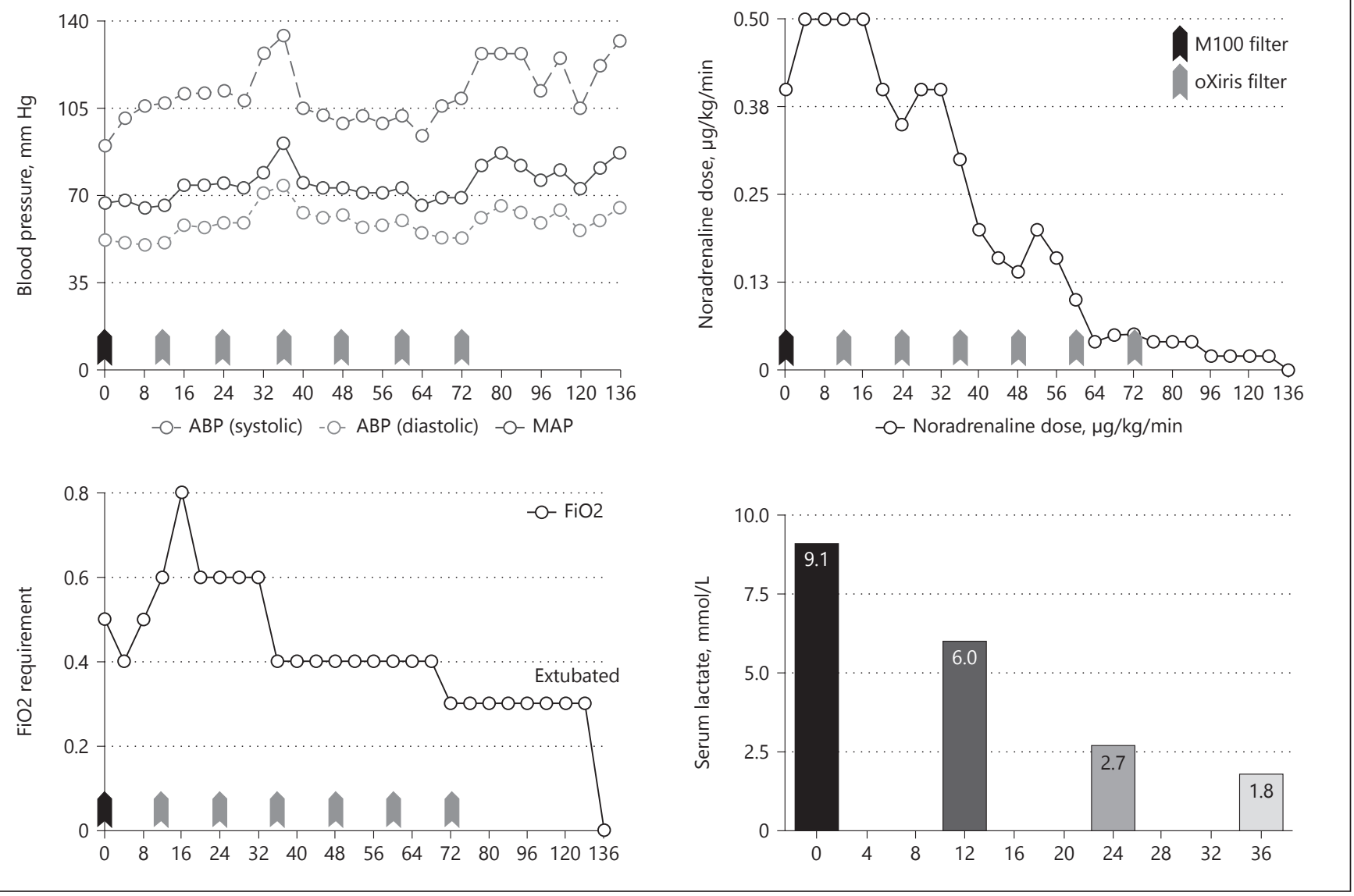

Fig. 1. Haemodynamics, gas exchange and vasopressor requirement during CVVHDF with oXiris. CVVHDF, continuous veno-venous haemodiafiltration.

tively change the haemofilter membrane before it actually clots. A study of AN69 haemofilters in CVVH compared 3 hourly filter change in a 9 -h period versus a $9 \mathrm{~h}$ period with the same AN69 haemofilter throughout CVVH [13]. The study suggested that elective 3 hourly haemofilter change was more effective than using the same haemofilter throughout CVVH in decreasing noradrenaline requirements in septic AKI patients as well as plasma cytokine concentrations in them.

We thus developed a blood purification protocol to electively change the oXiris haemofilter every $12 \mathrm{~h}$ for 3 consecutive days during CVVHDF using the Prismaflex CRRT machine. The first SA-AKI patient treated this way at our centre, as described aforementioned, manifested a definite clinical response with steady reduction of highdose vasopressor before the start of this frequent filter change regimen, to complete withdrawal of pharmacological haemodynamic support by the end of this period of "pulsed adsorption". There were concomitant im- provements in the patient's gas exchange, serum lactate levels and SOFA scores. As this is only a single patient, we are unable to draw any definitive conclusions but are able to generate the hypothesis that frequent filter change may ameliorate the course of severe septic shock, especially if the membrane possesses high affinity for humoural mediators of sepsis such as endotoxins and cytokines. Providing a new adsorptive membrane at a predetermined time interval affords fresh adsorptive binding capacity for renewed adsorptive clearance of these septic mediators thus possibly making a difference to the plasma mediator concentrations. The adverse clinical course and high mortality may thus be improved. Using such membranes in the conventional way till the circuit clots is more economical but overlooks the adsorptive binding property of the membrane and denies such septic AKI patients the full benefit of such membranes. The major critique of this report is that it involves only one patient, there were no controls and the fact that the patient could have been improv-
Tan/Kaushik/Tan/Liew/Teo/Loo/Ng/ Choong/Foo 
Table 2. Clinical and laboratory parameters following 3 consecutive days of 12 hourly oXiris filter change during CVVHDF

Pre-treatment parameters

Post-treatment parameters

Renal function (serum)

Urea, $\mathrm{mmol} / \mathrm{L}$

Creatinine, $\mu \mathrm{mol} / \mathrm{L}$

12.8

5.7

Potassium, mmol/L

4.9

105

Sodium, $\mathrm{mmol} / \mathrm{L}$

126

3.7

Bicarbonate, $\mathrm{mmol} / \mathrm{L}$

10.5

128

Urine volume, $\mathrm{mL} / 24 \mathrm{~h}$

10

23.8

Full blood count

$\mathrm{Hb}, \mathrm{g} / \mathrm{dL}$

9.2

410

Total white cell, $\times 10^{9} / \mathrm{L}$

17.7

8.4

Platelets, $\times 10^{9} / \mathrm{L}$

Coagulation

PT, s

21.1

21

aPTT, s

48.9

22.5

Plasma lactate, $\mathrm{mmol} / \mathrm{L}$

Vasopressor dose

Ventilator settings

$\mathrm{FiO} 2$

PEEP, $\mathrm{mm} \mathrm{Hg}$

PS, $\mathrm{mm} \mathrm{Hg}$

9.1

51.5

Noradrenaline: dose: $0.5 \mu \mathrm{g} / \mathrm{kg} / \mathrm{min}$

1.8

0 - off vasopressor

CVVHDF, continuous veno-venous haemodiafiltration; PS, pressure support.

ing already anyway before our pulsed adsorptive blood purification protocol was implemented. However, the patient was not on the verge of recovery before we used this protocol as evidenced by the increasing dose of vasopressor agent and oxygen requirement. We thus believe that frequent oXiris haemofilter change to augment pulsed adsorptive blood purification deserves further study and understanding to further expand therapeutic options for such patients with severe sepsis, septic shock and AKI.

\section{Acknowledgements}

The authors would like to thank our renal dialysis centre and ICU nursing colleagues in carrying out this treatment based on our newly developed protocol. We would also like to thank the Translational Medicine Office, Singapore General Hospital, for permitting the use of this non-standard treatment protocol.

\section{Statement of Ethics}

The Central Institutional Review Board of Singhealth-Duke Academic Medical Centre waived the need for informed consent and ethical review since this is only a case report of 1 patient. Informed consent was obtained from the next-of-kin with full disclosure of the potential benefits, risks and costs including a full assurance of continuation of prevailing ICU care should they have declined to be treated with the new blood purification protocol. oXiris ${ }^{\circledR}$ is approved for use in Singapore by the Health Sciences Authority, the local governmental regulatory body responsible for approving both drugs and devices.

\section{Disclosure Statement}

M.K.: received speaker fees from Baxter Healthcare (Asia). The other authors have no conflicts of interest to declare.

\section{Funding Source}

No funding for this study and preparation of the manuscript were received. The patients and their next-of-kin paid for their own treatment.

\section{Author Contributions}

All authors stated were either managing physicians of the patients in the report, contributed in sourcing for suitable cases to treat using our newly developed protocol, helped with informed consent taking and/or contributed to the development and operational maintenance of the hospital infrastructure, hardware and work processes ultimately necessary for the treatment to be carried out. 


\section{References}

1 Cole L, Bellomo R, Journois D, Davenport P, Baldwin I, Tipping P. High-volume haemofiltration in human septic shock. Intensive Care Med. 2001 Jun;27(6):978-86.

2 Reinhart K, Meier-Hellmann A, Beale R, Forst H, Boehm D, Willatts S, et al.; EASyStudy Group. Open randomized phase II trial of an extracorporeal endotoxin adsorber in suspected Gram-negative sepsis. Crit Care Med. 2004 Aug;32(8):1662-8.

3 Honore PM, Jacobs R, Joannes-Boyau O, De Regt J, De Waele E, van Gorp V, et al. Newly designed CRRT membranes for sepsis and SIRS-a pragmatic approach for bedside intensivists summarizing the more recent advances: a systematic structured review. ASAIO J. 2013 Mar-Apr;59(2):99-106.

4 Hattori N, Oda S. Cytokine-adsorbing hemofilter: old but new modality for septic acute kidney injury. Ren Repl Ther. 2016;2(1):41.

5 Shum HP, Chan KC, Kwan MC, Yan WW. Application of endotoxin and cytokine adsorption haemofilter in septic acute kidney injury due to Gram-negative bacterial infec- tion. Hong Kong Med J. 2013 Dec;19(6):4917.

6 Malard B, Lambert C, Kellum JA. In vitro comparison of the adsorption of inflammatory mediators by blood purification devices. Intensive Care Med Exp. 2018 May;6(1): 12.

7 Alvarez G, Chrusch C, Hulme T, PosadasCalleja JG. Renal replacement therapy: a practical update. Can J Anaesth. 2019 Feb.

8 Cole L, Bellomo R, Hart G, Journois D, Davenport $\mathrm{P}$, Tipping $\mathrm{P}$, et al. A phase II randomized, controlled trial of continuous hemofiltration in sepsis. Crit Care Med. 2002 Jan; 30(1):100-6.

9 Joannes-Boyau O, Honoré PM, Perez P, Bagshaw SM, Grand H, Canivet JL, et al. Highvolume versus standard-volume haemofiltration for septic shock patients with acute kidney injury (IVOIRE study): a multicentre randomized controlled trial. Intensive Care Med. 2013 Sep;39(9):1535-46.

10 Livigni S, Bertolini G, Rossi C, Ferrari F, Giardino M, Pozzato M, et al.; GiViTI: Grup- po Italiano per la Valutazione degli Interventi in Terapia Intensiva (Italian Group for the Evaluation of Interventions in Intensive Care Medicine) is an independent collaboration network of Italian Intensive Care units. Efficacy of coupled plasma filtration adsorption (CPFA) in patients with septic shock: a multicenter randomised controlled clinical trial. BMJ Open. 2014 Jan;4(1):e003536.

11 La Manna G, Donati G. Coupled plasma filtration adsorption: A multipurpose extracorporeal detoxification therapy. Blood Purif. 2018;46(3):228-38

12 Körtge A, Wild T, Heskamp B, Folk M, Mitzner S, Wasserkort R. Thrombogenicity and long-term cytokine removal capability of a novel asymmetric triacetate membrane hemofilter. J Artif Organs. 2018 Dec;21(4):43542.

13 Haase M, Silvester W, Uchino S, Goldsmith D, Davenport P, Tipping P, et al. A pilot study of high-adsorption hemofiltration in human septic shock. Int J Artif Organs. 2007 Feb; 30(2):108-17. 